\title{
School Violence in Contexts of High Social Marginalization and Ethnic Population of Yucatan, Mexico
}

\author{
Yolanda Oliva Peña, Andrés Santana Carvajal, Luis Cambranes Puc, \\ Ricardo Ojeda Rodríguez \\ Regional Research Center “Dr. Hideyo Noguchi” of the Autonomous University of Yucatan, Mérida, Mexico \\ Email: opena@correo.uady.mx
}

How to cite this paper: Peña, Y. O., Carvajal, A. S., Puc, L. C., \& Rodríguez, R. O. (2018). School Violence in Contexts of High Social Marginalization and Ethnic Population of Yucatan, Mexico. Psychology, 9, 2897-2908.

https://doi.org/10.4236/psych.2018.915168

Received: November 3, 2018

Accepted: December 21, 2018

Published: December 24, 2018

Copyright $\odot 2018$ by authors and Scientific Research Publishing Inc.

This work is licensed under the Creative

Commons Attribution International

License (CC BY 4.0).

http://creativecommons.org/licenses/by/4.0/

\section{(c) (i) Open Access}

\begin{abstract}
The objective of this work was to determine the magnitude and frequency of school violence in the eastern part of the state of Yucatan, Mexico, which is populated primarily by Maya-speakers and also by communities of high social marginalization, factors associated with adolescence, and the condition of gender, by contexts that have been poorly documented in the face of the phenomenon of violence in secondary schools. Quantitative study through a self-applied survey of 1432 high school students is possible to conclude that the conditions of gender, social and ethnic marginalization are elements that come together in vulnerabilities to present violence in social contexts with a strong magnitude. The students show similar proportions of violence in to teachers (93\%), a significant difference in women than the recorded by men $(p=0.000)$, with a greater number of cases in moderate and severe intensity. Peer violence is manifested a statistically significant difference by men and women, in which women reflect a greater intensity, with a higher number of cases in violence of moderate and severe intensity $(p=0.000)$.
\end{abstract}

\section{Keywords}

School Violence, High Social Marginalization, Ethnic, High School, Yucatan

\section{Introduction}

The World Health Organization defines violence as the deliberate use of physical force or power, whether in a threatening or effective manner, against oneself, another person or a group or community, which causes or is likely to cause injury death, psychological damage, death, development or deprivation disorders 
(Amemiya et al., 2009). At school, the violence can also be presented among students' acts of violence like persecution, disqualification, stigmatization or aggression against another, which can also be recognized as "bullying", a term that refers to the establishment and maintenance of unbalanced power relations between subjects. It's important to say that the students coexist in shared contexts of the school environment during extended periods of time, in which dynamics of domination and submission are established that lead to aggressions of those who exercise power abusively towards those who are subjected to the role of whites or victims of those abuses (Aviles, 2006; Olweus, 1978, 1998; Ortega 1992). At the school, the adult plays a fundamental role at the time that an act that involves violence is presented in order to mediate violent behaviors using reflective processes and the application of corrective consequences all this with joint activities between adult staff and students of institutions, hence the importance of knowing the dynamics of social relationships and the prevalence of relationships based on violence and oppression and/or social exclusion.

School violence is a topic that was studied a little over two decades ago, however, being a complex problem involving multiple factors has been addressed from different approaches and with a diversity of studies and instruments, as well as the conceptualization used. Violence, bullying or school mistreatment are complex phenomena that emerge in the context of coexistence; framed in the norms, routines, processes, interaction and exchange systems, subjectivities and cultural guidelines of each school institution (Román \& Murillo, 2011). At present, it is admitted as a multiform way of exercising abuse among students in school contexts. Prior to the definition of Olweus (1993) that exemplified the abuse between equals when "a scholar suffers violence or harassment ("mobben"), when repeatedly and prolonged is subjected to negative acts of another or other school". "A student is assaulted or becomes mistreatment between equals: victim bullying when he is exposed, repeatedly and for a time, to negative actions carried out by another student or several of them" (Olweus, 1998: p. 25), is particularly relevant to Roland and Munthe (1989) who defined it as prolonged violence that is repeated, both mentally and physically, carried out by an individual or group and directed against an individual who is not capable of defend yourself against this situation by becoming a victim. Subsequently, in the definition of school violence with which includes social, psychological, moral damages, etc. have been admitted. Therefore, today the concept of abuse between peers and/or school bullying includes these consequences through a typology of forms, backgrounds and execution scenarios. The concept of school violence does not give complete clarity, although all definitions share the fact that there is intentionality to cause harm. "School violence covers all activities and actions that cause pain or physical or mental injuries to people who act in the school environment, or who seek to damage objects that are in that area." This definition allows us to consider various manifestations of violence and the participation of different people in schools (Tijmes, 2012).

The topic of school violence in adolescence can mainly be approached from 
two different points of view. If we consider the behavior problems in high school as a manifestation of the increase of the violence that is lived in the schools at the moment, as it does Rosario Ortega, where it mentions that everything that undermines the bases of the peaceful coexistence is violent. On the one hand, it is identified as a set of phenomena that affect good coexistence and, on the other hand, as direct physical aggression between people at the school. Mentioned above we can differentiate five categories (Ortega, 2001): vandalism, or violence against the belongings of the school; Disruption, or violence against school work; indiscipline, or violence against school rules; interpersonal violence and violence that can become problematic of a criminal nature. Also we can say that there are different ways of approaching their study, paradigms and different disciplines for the attention of the phenomenon of school violence. From the psychological point of view, attention has focused on the practices and behaviors linked and involved in the phenomenon of bullying among peers, especially in aggressive and violent behavior and the problem of victimization in its different expressions and consequences for those affected (Román \& Murillo, 2011). The aggressions between other students affect in an important way not only the emotional and behavioral aspects of those involved, but also and significantly learn and achieve in essential disciplines for their training and development. However, situations or acts of violence between peers are frequent and usually invisible to teachers, which makes it more complex to react and intervene to prevent them (Román \& Murillo, 2011).

From the sociological perspective, it has deepened in the identification of social factors linked to bullying such as poverty, social exclusion, juvenile delinquency, alcohol and drug consumption, as well as youth culture, in order to recognize and prevent its incidence and reduce risk behaviors (Román \& Murillo, 2011). In these paper, school violence is study of perspective sociological, to know the role exercised by various social actors who hold physical, psychological or social hierarchy, i.e. actors such as teachers, school authorities or between boys and girls with violent male power, also, the role the gender in the violence, and what type of violence predominates.

Among the antecedents in the study of school violence is the study conducted in 1993 in Europe, where the Whitney and Smith, finding a rate of victimization of $10 \%$ for England, while $6 \%$ of students were recognized as aggressors. Ten years later, according to Dake, Price and Telljohann (2003), the prevalence figures for bullying ranged from 11\% (Finland) to $49 \%$ (Ireland), and in the United States the percentage was close to $20 \%$. In Spain, one in four students is a victim of school violence, seven times higher in primary than in high school. In Australia, $17.4 \%$ report being victims of severe bullying, while $31 \%$ report having suffered bullying or abuse of medium type (Román \& Murillo, 2011). A study carried out in several European countries indicates, first, that approximately half of the students have seen or participated in intimidation behaviors that have to do with insults, bad words in class or fights. Particularly, high values are given in Austria and France, being somewhat lower in Spain and significantly lower in 
Hungary. As for gender, it is the boys who feel most personally affected by the insults and bad words in class, which may be due to a greater severity in the "verbal aggressions" in males (Cangas et al., 2007).

Most bullying occurs at school, rather than on the way to or from school. Assailants and victims are generally in the same grade level, and while minors are supposed to be supervised at school, most episodes of harassment are not known to teachers and the victim usually feels unable to report them to these and their parents. Craig et al, in 2009 reported that the prevalence of bullying in 40 countries with representative national samples was $8.6 \%$ to $45.2 \%$ in males and $4.8 \%$ to $35.8 \%$ in females. In addition, $10.2 \%$ were identified as aggressors, $12 \%$ as victims and 3\% as aggressor-victim (Albores-Gallo et al., 2011). Also, in Spain, it was reported that for 2006 they suffered verbal abuse between 27 and $32 \%$ of high school students; Secondly, abuse due to social exclusion was found, and in less than 1\%, blackmail and sexual harassment were observed. This work and a first study carried out in 2000 observe that, in Spain, in general terms, men are more involved than women in abusive behavior The Ombudsman (2007).

In 2007 Plan International, an international non-governmental organization carried out a study on school violence in 49 developing countries and 17 developed countries. There are identified three main areas or types of violence that affect children in schools: corporal punishment, sexual violence and bullying (school harassment). Regarding the latter, the study found that bullying is a common behavior in schools around the world, and that students affected by school harassment generally develop problems of concentration and learning difficulties.

In Latin America, the analyzes carried out by UNESCO (Llece, 2001), in the first international comparative study at the regional level, showed better performances in the students who reported few situations of violence in the school (fights and others) and in those centers where friendship relations are established (Román \& Murillo, 2011). Accordingly, the magnitude of violence among peers in Latin American schools is a phenomenon that hits more strongly than in other regions, being even more serious and complex in some of their countries. In contrast to the $63 \%$ of primary school students who claim to be victims of bullying in Colombia, in Cuba this figure is only 13\%. In this broad spectrum, three groups of countries were formed. A first group where more than half of its students declare themselves victims of some type of harassment or mistreatment by peers (Colombia, Costa Rica, Argentina, Ecuador, Panama and the Dominican Republic); a second group where students who have been victimized represent between $40 \%$ (Uruguay, Paraguay, Nicaragua) and 50\% of the total (Brazil, Peru, Mexico, Guatemala, El Salvador and Chile), and finally, a third group integrated only by Cuba (13\%). The foregoing shows that both prevention actions and those aimed at reducing bullying must be different between countries (Román \& Murillo, 2011).

In the studies carried out in Latin America, there are also differences between countries and with respect to the level of education. In private and public 
schools in Brazil, the percentage of primary school students who recognize being repeatedly threatened ranges from $21 \%$ to $40 \%$, depending on the geographical area. With respect to Peru, the data indicate a bullying rate of $47 \%$ (Oliveros et al., 2008), while in Chile $11 \%$ of students report having suffered bullying, whether they are permanent threats, discrimination or both from their peers (National School Violence Survey, 2007). In Argentina, almost a third of high school students admit having suffered the breakage of tools or other objects taken to school (32\%). Verbal violence reaches percentages between $12 \%$ and $14 \%$, depending on the degree. $10 \%$ of students say they have suffered threats from a partner, while $8 \%$ have been victims of social violence or exclusion (Román \& Murillo, 2011). In Nicaragua, Del Rey and Ortega (2008) found that in secondary education the involvement was $35 \%(12.4 \%$ as a victim, $10.9 \%$ as aggressor and $11.7 \%$ as bully-victim) (Felix et al., 2011).

School violence and bullying in the case of Mexico, in Guadalajara, it was reported that up to $68 \%$ of the students surveyed had been intimidated at some point (Valadez-Figueroa, 2008). A study conducted with more than one million high school students, from different cities in Brazil and also in the Federal District, Mexico, documented that $83.4 \%$ had mentioned the existence of bullying in their school (Abramovay, 2005). Of the recently published reports, the National Health and Nutrition Survey (ENSANUT) stands out in 2006, which documented that almost a quarter of the respondents had been victims of bullying at some time, while the Ministry of Public Education (SEP), in collaboration with UNICEF in 2009 , they reported among other things that $43.2 \%$ of teaching staff knew of the presence of bullying in their schools. Also, at Mexico, in Merida, Yucatan, south of the country, a study in high school students found that $74.6 \%$ of young people observe that in their schools there are classmates who are ignored and left alone, while 59\% indicated that there are young people who do not they are allowed to participate in activities. Verbal aggression was the most common form of peer abuse according to students' perception. According to what is reported, it is a widespread form of violence: $85.4 \%$ observe the presence of offensive nicknames among their peers and $85.5 \%$ realize that their peers speak badly of one another. Insults, although they are less frequent than other forms of aggression, also represent a widespread practice, 78.2\% of observers (Castillo Rocha \& Pacheco Espejel, 2008). This same study reports that the identification of blows was not as frequent as verbal abuse, however, its presence is also very important in schools, and reaches a presence of 66.3 percent property damage. The students reported, in $53.5 \%$, that in their school someone breaks the things of one of their classmates (Castillo Rocha \& Pacheco Espejel, 2008). In this study, as expected, because of the difference between being an observer and being an actor, the incidence of abuse suffered by the interviewees is reported in a much lower frequency in relation to the perceived one. It should be noted that there is no form of aggression that is reported with a zero frequency in either men or women, but those with percentages of occurrence less than 10 are the same that represent less frequency in perceived abuse, these are: sexual harass- 
ment (6.7\%) and threats with sticks, knives or other objects (3.6\%) (Castillo Rocha \& Pacheco Espejel, 2008). Although factors such as size of the school: large schools are more prone to violence, poverty or crime level of the area where the center is located, the educational stage of students: high school students are more likely to suffer fights, fights, among others, are good predictors of school violence. Teachers' attitudes to harassment situations, the degree of supervision of leisure activities and the existence of an effective school policy against bullying are important (Nickerson \& Martens, 2008).

Finally, work on relationships that favor human development with equity and exercise power for autonomy and self-esteem, not to dominate or harm, as it happens in violent environments, exercised by the macho, homophobic, misogyny, and discriminatory power that emerges from a culture of inequitable and dominant gender, is the task that occupies us in this study, on violence, the state of schools, taking into account as transversal axes gender, ethnicity and high social marginalization.

\section{Methodology}

The study methods were: Quantitative, observational, analytical, cross-sectional. The design of the sample was simple randomized after degree of marginalization. The target population of the eastern region of the state of Yucatán consists of 76 secondary schools. The sample population with $95 \%$ confidence was 30 schools and a total of participants from 4 municipalities, with 17 locations that have secondary schools of any kind. The final sample was of 22 schools with a total of 1432 participating students, localities of high marginalization in $86.36 \%$ and of marginalization only 3 schools.

The data collection was carried out through a self-applied structured questionnaire (CUVE3-EP), designed to evaluate school violence, validated in the Latin American population by Alvarez et al. (2015). The questionnaire evaluates the frequency with which the students consider that the different types of violence occur in the school include 36 items with Likert Scale answers of 5 options. The questionnaire inquires about the violence exerted by the teachers towards the students, and the violence that is exerted among the students, as well as the students towards the teaching staff. The dimensions that it deals with are: verbal violence that refers to nicknames, to speak badly, to speak with bad words, threats, ridicule, and disrespect. The types of violence are divided into direct and indirect, direct physical violence and threats such as putting fear, hitting, pinching, pulling hair, physical aggression near the school grounds, cause fights. Indirect physical violence considers stealing, damaging, or hiding belongings, and social violence is eject, not accept by low notes without participating in team activities, or exclude in recreational activities, for their religion, ignore.

This questionnaire includes the violence exercised by teachers towards students and violence between peers; the types of violence are divided into direct and indirect physical, direct and indirect verbal, social violence and/or social exclusion, which measures frequency and intensity, where the following levels are 
recognized, absence $=0$, mild as an average of 1 , average with average values of 2 to 3 and severe of 4 and more. To carry out the processing of the information, the SPSS program version 22 will be used. Contingency tables will be applied for the comparison of prevalence by sex and type of violence, as well as by intensity. Student's $\mathrm{T}$ test was used to determine differences in meanings by sex and type of school violence, with $p<0.05$. The questionnaire was applied prior informed consent of parents and the student.

\section{Results}

The final sample is distributed by sex in $50.6 \%$ men and $49.4 \%$ women, with a minimum age of 12 years and a maximum of 18 . The $72.3 \%$ speak Mayan regularly, and inhabit in localities of high marginalization $68.8 \%$ of the total sample. It was found that $96 \%$; The analysis by type of perceived violence highlights verbal violence, followed by violence of social exclusion, followed by direct physical violence and finally indirect physical violence (Table 1).

Regarding the violence exerted by the teacher towards the student, it is observed that verbal violence predominates, in second place the social violence, followed by direct physical violence and finally the indirect physical violence. it is observed that women perceive more the social violence and the indirect physical violence in comparison to the men, that is to say they feel excluded or mistreated in their belongings by the teachers (Table 2).

Students report by type of violence exerted by teachers towards them, according to the violence intensity parameters, which is direct physical violence which registers a percentage of 38.4 for men and 44.5 for women in a moderate to moderate intensity. severe, occupying the first place in importance. The second place is recorded by indirect physical violence with $13.1 \%$ and $20.5 \%$ respectively; the third place is occupied by social exclusion violence with $8.8 \%$ for men and $15 \%$ for women and finally verbal violence with percentages of

Table 1. Types of violence according to percentage.

\begin{tabular}{lc}
\multicolumn{1}{c}{ Types of violence } & Percentage \\
\hline 1) Violence exercised by teachers towards students & 93 \\
Direct physics teaching staff & 82.4 \\
Teacher's indirect physics & 68.6 \\
Social teaching staff & 86.7 \\
Verbal teachers & 91 \\
2) Peer violence & 95 \\
Verbal of the student & 84.2 \\
Direct physics of the student & 78.1 \\
Student's indirect physics & 68.7 \\
Social students & 81.2 \\
\hline
\end{tabular}

Source: Own elaboration. 
Table 2. Percentage distribution by type of violence by teachers.

\begin{tabular}{ccccc}
\hline Sex & Direct physical violence & Indirect physical violence & Verbal violence & Social violence \\
\hline Men & 83 & 65.6 & 90.5 & 84.9 \\
Women & 81 & 71.7 & 91.4 & 90.4 \\
\hline
\end{tabular}

Source: Own elaboration.

$6.7 \%$ and $13 \%$ respectively. It should be noted that in all types of violence women show greater intensity than men, differences that are significant and can be seen in $\mathrm{p}$-values by type of violence, with a value of $p<0.05$ (Table 3 ).

Violence among students reveals that direct verbal violence has a greater weight, followed by violence of social exclusion, followed by direct and indirect physical violence and finally indirect verbal violence, types of violence in which women refer percentages higher, primarily in direct verbal violence and social exclusion (Table 4).

The violence that is exerted by the students according to the intensity is the indirect physical violence which groups higher percentages of the average level, with $84.2 \%$ for men and $90.4 \%$ for women; the second place is occupied by direct physical violence with percentages of $17.3 \%$ and $25.5 \%$ for men and women respectively, in the range of medium to severe intensity, where the severity is manifested by $4.4 \%$ of women. In the third place, the violence of social exclusion is located with $11 \%$ and $19.3 \%$ respectively for men and women in a range from medium to severe; Fourth, indirect verbal violence is located with $11 \%$ and $17 \%$ and finally direct verbal violence with $8.95 \%$ and $12.3 \%$ for men and women respectively. These differences by sex were significant for all types of violence at a level $p<0.05$ (Table 5).

\section{Conclusion}

In our current society, although great advances have been made in terms of gender equity, aspects of our culture that promote the continuity of violent behavior and dominant positions still continue, among them the predominance of the culture of the hierarchies, where the domination and strength of the character with the highest hierarchical level occur on recurrent occasions, continuously limiting the correct dialogue and the appropriate reflexive process among the members. The behaviors of what should or should not be according to their gender, up to the expectations of the behavior of others, these concepts that the individual generates transcend several times to schools, where violence occurs in some of the ways that could be: Words that humiliate, submission, fear, abuse of power, beatings, insults, neglect and indifference, discrimination, absence of social assistance, etc.; Women and men are repeatedly imprisoned in these social stereotypes because, if women in a socialization job tend to discredit them and undermine them by tasks considered by society as if they were their own role, they develop a negative learning of repression, silence and resignation. Men are also prisoners of dominant role representation, even before their own sex, where 
Table 3. Values of $\mathrm{p}$ in types of violence by teachers.

\begin{tabular}{cc}
\hline Types of violence by teachers & $p$-value for differences by sex \\
\hline Direct verbal & $p=0.000$ \\
Direct physical & $p=0.001$ \\
Indirect physical & $p=0.000$ \\
Social & $p=0.000$ \\
Total & $p=0.000$ \\
\hline
\end{tabular}

Source: Own elaboration.

Table 4. Percentage distribution of peer violence by type.

\begin{tabular}{cccccc}
\hline Sex & Direct physical violence & $\begin{array}{c}\text { Indirect physical } \\
\text { violence }\end{array}$ & $\begin{array}{c}\text { Direct verbal } \\
\text { viol }\end{array}$ & Indirect verbal & Social viol \\
\hline Men & 76.7 & 65.6 & 83 & 64.5 & 79 \\
Woman & 79.7 & 71.7 & 85.5 & 69 & 83.5 \\
\hline
\end{tabular}

Source: Own elaboration.

Table 5. P-value for differences by sex in types of violence by students.

\begin{tabular}{cc}
\hline Types of violence by students & $p$-value for differences by sex \\
\hline Direct Verbal & $p=0.004$ \\
Indirect Verbal & $p=0.017$ \\
Direct physical & $p=0.000$ \\
Indirect physical & $p=0.000$ \\
Social & $p=0.000$ \\
Total & $p=0.000$ \\
\hline
\end{tabular}

Source: Own elaboration.

competition often predominates to manifest control and power of what they perceive as weaker. In the same way of the inclination to submission and repression, the forms that lead to the demand and exercise of domination are not inscribed in the nature of being and must be built through an extensive process of socialization.

With respect to the social factors involved in the systematic occurrence of violence, students report having received similar proportions of violence in addition to teachers (93\%) and students (95\%). Women report experiencing it more intensely and frequently in most types of violence. It is possible to conclude that the conditions of gender, social marginalization and ethnicity constitute elements that converge in vulnerabilities to present violence in social contexts with a great magnitude and in what refers to the seriousness.

\section{Discussion}

Social and cultural contexts characterized by social marginalization and ethnic status, as the case studied here, can be constructed as spaces of social interaction that protect or promote violence as a form of hierarchical exercise at the com- 
munity, society, and community level. School in particular, as a microsocial expression of the relations between genders guided by the context determined historical moment. The school expresses the multiple interactions, and the concrete forms assumed by the hierarchical societies. In this study, higher prevalence was registered in previous studies, as is the case of a study carried out with high school students from various cities in Brazil and the Federal District, Mexico, which records that $83.4 \%$ of the existence of bullying in their school (Abramovay, 2005); 74.6\% was reported by Castillo Rocha \& Pacheco Espejel (2008), and in Guadalajara it was reported that up to $68 \%$ of the students surveyed had been intimidated at some point (Valadez-Figueroa, 2008), studies conducted in non-indigenous urban areas, compared to $96 \%$ reported by our study, referring mainly to marginalized and indigenous areas, which may explain vulnerabilities added to what has been recorded so far.

Likewise, it is important to point out that although the types of violence with an intensity level observed predominantly at a slight level are significant, those related to teacher violence and among students regarding physical violence and social exclusion experienced are significant. with greater intensity for women, which means, on the one hand, a possible normalization on the part of men regarding the intensity with which it is lived, as a habitual phenomenon, normal violence and on the part of girls, as a phenomenon that It has not been naturalized and that is lived by its condition of being poor and indigenous women.

Until the moment there has been little emphasis in the analysis of gender in the studies of school violence, this study provides an important key to deepen and understand the complex dynamics of the school's interactions, under a micro social approach, from a perspective of gender, social class and ethnicity, to understand progress and difficulties in constructing egalitarian spaces, and a culture of peace in our Latin American contexts and in Mexico particularly in the face of cultural diversity and the presence of multiple contexts of high social marginalization that need to be addressed with particular educational policies, incorporating processes that attend in the first instance to teachers who are in schools to sensitize them and motivate the change in the styles of education oriented to the construction of gender equality and nonviolence.

\section{Conflicts of Interest}

The authors declare no conflicts of interest regarding the publication of this paper.

\section{References}

Abramovay, M. (2005). Violence in Schools, a Great Challenge. https://rieoei.org/historico/documentos/rie38a03.pdf

Albores-Gallo, L., Sauceda-Garcia, J. M., Ruiz-Velasco, S., \& Roque-Santiago, E. (2011). Bullying and Its Association with Psychiatric Disorders in a Sample of Schoolchildren in Mexico. Public Health of Mexico, 53, 220-227.

Alvarez-García, D., Mercedes, J. M., Rodríguez, F. J., \& Núñez, J. C. (2015). Adaptación y 
validación del cuestionario CUVE 3-EP para la evaluación de la violencia escolar en centros de enseñanza básica de la República Dominicana. Anales de Psicología, 31, 859-868.

Amemiya, I., Oliveros, M., \& Barrientos, A. (2009). Risk Factors of School Violence (Bullying) Severe in Private Schools in Three Areas of the Mountains of Peru. In Anales de la Faculty of Medicine (Vol. 70, No. 4, pp. 255-258). UNMSM. School of Medicine. https://doi.org/10.15381/anales.v70i4.925

Aviles, J. M. (2006). Bullying: The Abuse between Equals. Aggressors, Victims and Witnesses in the School. Salamanca: Amarú Ediciones.

Cangas, A. J., Gázquez, J. J., Pérez-Fuentes, M. C., Padilla, D., \& Miras, F. (2007). Evaluation of School Violence and Its Personal Involvement in a Sample of European Students. Psicothema, 19, 114-119.

Castillo Rocha, C., \& Pacheco Espejel, M. M. (2008). Profile of Bullying among High School Students in the City of Mérida, Yucatán. Mexican Journal of Educational Research, 13, 825-842.

Craig, W., Harel-Fisch, Y., Fogel-Grinvald, H., Dostaler, S., Hetland, J., Simons-Morton, B., Pickett, W., et al. (2009). A Cross-National Profile of Bullying and Victimization among Adolescents in 40 Countries. International Journal of Public Health, 54, 216-224. https://doi.org/10.1007/s00038-009-5413-9

Dake, J. A., Price, J. H., \& Telljohann, S. K. (2003). The Nature and Extent of Bullying at School. Journal of School Health, 73, 173-180. https://doi.org/10.1111/j.1746-1561.2003.tb03599.x

Del Rey, A. R., \& Ortega, R. (2003). Violence in the School.

Felix, E. M. R., Alamillo, R. D. R., \& Ruiz, R. O. (2011). Prevalence and Differential Aspects Related to the Gender of the Bullying Phenomenon in Poor Countries. Psicothema, 23, 624-629.

Nickerson, A. B., \& Martens, M. P. (2008). School Violence: Associations with Control, Security/Enforcement, Educational/Therapeutic Approaches, and Demographic Factors. School Psychology Review, 37, 228-243.

Oliveros-Donohue, M. A., Figueroa, A., Mayorga-Ricalde, G. S., Cano-Uria, C. B., Quispe, A., \& Barrientos-Achata, A. (2008). School Violence (Bullying) in State Primary Schools in Peru. Revista Peruana de Pediatría, 61, 215-220.

Olweus, D. (1978). Aggression in the Schools: Bullies and Whipping Boys. Washington, DC: Hemisphere.

Olweus, D. (1993). Bullying at School. What We Know and What We Can Do. Oxford: Blackwell.

Olweus, D. (1998). Harassment and Threat Behavior among School Children. Madrid: Morata.

Ortega, R. (1992). Violence in Schools: Bully-Victims Problems in Spain. Presented in 5 th European Conference on Developmental Psychology, Seville.

Ortega, R. (2001). The Andave Projet: A Ecological Educational Approach for a Cosmopolitan Citizenship.

Roland, E., \& Munthe, E. (1989). Bullying, an International Perspective. London: David Fulton.

Román, M., \& Murillo, F. J. (2011). Latin America: Violence between Students and School Performance. Violence and School Climate in Educational Establishments in Contexts of High Social Vulnerability in Santiago de Chile. Psykhe (Santiago), 21, 105-117. 
Secretary of Public Education. UNICEF Mexico (2009). National Report on Gender Violence in Basic Education in Mexico 2009. Mexico: SEP.

Tijmes, C. (2012). Violence and School Climate in Educational Establishments in Contexts of High Social Vulnerability in Santiago de Chile. Psykhe, 21.

UNESCO, Llece (2001). First International Comparative Study on Language, Mathematics and Associated Factors, for Students of the Third and Fourth Grade of Basic Education. http://unesdoc.unesco.org/images/0014/001492/149268s.pdf

Valadez-Figueroa, I. (2008). School Violence: Peer Abuse in High Schools in the Metropolitan Area of Guadalajara. Study Report, Childish, Educational Processes Series, Mexico: Maternal Health Collection. 